Received 28 April 2019, Accepted 19 June 2019

Link to DOI:

10.25220/WNJ.V03.i1.0003 Journal Website:

www.worldnutrijournal.org

\title{
Fructose Intake and Its Correlation with Carotid Intima-Media Thickness in Male Employees with Hypercholesterolemia in Harapan Kita National Cardiovascular Center Hospital, Jakarta, Indonesia
}

Astiti Dwi Arumbakti, ${ }^{1}$ Saptawati Bardosono, ${ }^{1}$ Bambang Budi Siswanto ${ }^{2}$

1. Department of Nutrition, Faculty of Medicine, Universitas Indonesia, Dr. Cipto Mangunkusumo General Hospital, Jakarta, Indonesia

2. Department of Cardiology, Faculty of Medicine, Universitas Indonesia, Harapan Kita National Cardiovascular Center, Jakarta, Indonesia

\begin{abstract}
Introduction Atherosclerosis is the main cause of cardiovascular disease that is detectable early by ultrasound examination of the carotid intima-media thickness (IMT). One of the risk factors is dyslipidemia, which can be affected by high fructose diet. Methods This cross sectional study was conducted to investigate the correlation between fructose intake and IMT in male subjects with hypercholesterolemia aged 19-49 years old. Data analyzed by using Statistical Package for Social Sciences (SPSS) version 20.0. Univariate analysis with normality test Kolmogorov-Smirnov. Bivariate analysis was using Pearson or Spearman correlation test. Results Of 47 subjects, median age was 41 (33-45) years old. In 57.4\% subjects, low density lipoprotein (LDL) was found high and very high levels, $29.8 \%$ subjects have low high density lipoprotein (HDL) level, and $27.6 \%$ subjects have high and very high triglycerides levels. Most subjects have normal systolic and diastolic blood pressure. Around $72.3 \%$ subjects were classified as obese and $66.0 \%$ were classified as having central obesity. Majority of subjects were light smoker and $49.8 \%$ performed light activity. In IMT carotid examination, median of $1(0.8-1.4) \mathrm{mm}$ was found with $63.8 \%$ subjects developed thickness. Median total energy intake was 1209 (1020-1645) Kcal/day, mostly with adequate carbohydrate, protein, and fat, fiber intake was inadequate in $100 \%$ subjects, and mean fructose intake of $31,97 \pm 15,48$ gram/day. Bivariate analysis did not demonstrate any correlation between fructose intake and carotid IMT. Conclusion There was no correlation between fructose intake and carotid IMT.
\end{abstract}

Keywords atherosclerosis, fructose, hypercholesterolemia, intima-media thickness

Organization (WHO) in 2012 reported 17.5 million

\section{Introduction}

Cardiovascular disease is the number one cause of death in the world. Data from World Health

Corresponding author:
Astiti Dwi Arumbakti
Department of Nutrition, Faculty of Medicine,
Universitas Indonesia, Jakarta, Indonesia
Email address: astitida@gmail.com
$(31 \%)$ of death annually due to cardiovascular disease. Of those numbers around 7.4 million deaths were due to coronary heart disease. ${ }^{1}$ Atherosclerosis is the main cause of cardiovascular disease that usually develop gradually over the years before overt clinical symptoms appears. ${ }^{2-6}$ One way to examine atherosclerosis can be performed by measuring intima-media thickness (IMT) using non-invasive methods with ultrasonography. American Heart Association recommended the IMT measurement as the best 
method to identify the presence of atherosclerosis. ${ }^{7}$ One of the modifiable risk factor of atherosclerosis is dyslipidemia. ${ }^{3,6}$ Data in Indonesia according to Basic Health Research or Riset Kesehatan Dasar (Riskesdas) in Biomedical in 2007 showed that prevalence of dyslipidemia based on total cholesterol levels $>200 \mathrm{mg} / \mathrm{dl}$ were $39.8 \%{ }^{4}{ }^{4}$

Several studies suggested that blood cholesterol levels can be affected by food intake, one of them is high carbohydrate diet particularly simple carbohydrate that correlated with increased level of triglycerides and decreased level of high density lipoprotein (HDL). ${ }^{8,9}$ According to result analysis from Individual Food Consumption Survey (Survei Konsumsi Makanan Individu/SKMI) in 2014 reported that consumption of sugar and confectionary category by Indonesian people was 15.7 gram per person per day, amongst them the most consumed in this category was cane sugar (13.6 gram/person/day). The proportion of population who consumed sugar more than 50 grams, was found the highest in the age group above 55 years old (6. 8\%) and the lowest in age group $0-59$ months (1.3\%). Meanwhile according to gender, more male individuals $(6.4 \%)$ consumed sugar more than 50 grams compared to female $(3.1 \%) .{ }^{10}$

Fructose is a monosaccharide mainly contained in honey along with glucose, also in fruits, flower nectar, and vegetables. Fructose can be processed and used commercially as sweeteners. Light beverages largely utilize high fructose corn syrup as sweetener substance. ${ }^{11-2}$ According to SKMI 2014 beverages in package were consumed by $8.7 \%$ of population, followed by other beverage $(1.8 \%)$, carbonated beverages $(1.1 \%)$, and the lowest alcohol containing beverages (0.2\%). Beverages in package were the most consumed in all age groups. ${ }^{10}$

Various studies demonstrated that as consumption of food/beverage containing fructose increased, a rise in prevalence of various symptoms of metabolic syndrome such as dyslipidemia, central obesity, hypertension, hyperuricemia, and type 2 diabetes mellitus was observed. ${ }^{12}$ A review article of fructose effect on post prandial triglycerides by Kolderup et.al. ${ }^{13}$ showed that normal fructose consumption (approximately 5060 gram/day) did not increased risk of atherosclerosis, type 2 diabetes mellitus, or obesity more than other sugar consumption. However, fructose high consumption especially when combined with other high energy intake in the form of glucose, may exert negative effect to health. A study by Soo et.al. ${ }^{14}$ on high fructose and its correlation with cardiovascular disease in rats during growing period resulted in an increased of total fat weight, increased serum triglycerides levels, and increased aorta abdominal wall thickness. Meanwhile, Bo et.al. ${ }^{15}$ conducted a study on rabbits (Watanabe heritable hyperlipidemic rabbits) demonstrated that atherosclerosis increased significantly on high fructose and high fat diet.

By recognizing atherosclerosis risk factors particularly those of modifiable amongst other food/beverage intake and early detection by examining carotid IMT also based on sugar and beverage in packages consumptions in Indonesian population who largely utilize fructose as sweetener substance, this study was conducted to investigate the correlation between fructose consumption and carotid IMT in adult subjects with hypercholesterolemia anticipating to prevent cardiovascular disease.

\section{Methods}

\section{Subjects and Study Design}

This study with a cross sectional design was conducted in Harapan Kita National Cardiovascular Center Jakarta started in December 2017 that aimed to investigate the correlation between fructose consumption and carotid IMT in adult subjects with hypercholesterolemia. This study is part of Dr. Diana Sunardi, M.Gizi, SpGK et.al. research titled "The Effect of Giving Milk Formula Enriched with Soluble Fibers on Lipid Profile Improvement in Adult Male Subjects with Mild to Moderate Hypercholesterolemia". This study was obtained ethical approval from Medical Research Ethics Committee of Faculty of Medicine University of Indonesia with number 819/UN2.F1/ETIK/VIII/2017. Inclusion criteria for subjects were males, age between 19-49 years old, total cholesterol levels $\geq 200 \mathrm{mg} / \mathrm{dl}$ and agreed to take part in the study by signing informed consent. Subject exclusion criteria including having history 
of cardiovascular disease, diabetes mellitus or impairment in liver functions as identified by history taking and also consuming drugs that may affect lipid or glucose metabolism within 3 months from history taking. Out of 139 hospital's employees who enrolled in the selection process, 47 subjects met the study criteria.

\section{Data collection}

Subject characteristic data collection included age, education, and income was conducted by interview. Food intake data (total energy, carbohydrate, protein, fat, and fibers) was collected by using 24hours foods recall and for fructose intake by using semi-quantitative food frequency questionnaire. Data obtained were converted to gram by using food substance analysis list and analyzed with Nutrisurvey for windows 2007 software. Physical activities assessment (physical activity level/PAL) was determined based on duration and types of activities routinely done during 24 hour-period. Degree of smoking was determined by Brinkman Index (BI).

Anthropometric measurement includes body weight (BW), body height $(\mathrm{BH})$, and waist circumference. Body weight was measured by using a weight scale (SECA brand), body height measurement using Microtoise staturemeter and waist circumference with an unstretchable tape (SECA). BW and BH data were used to calculate body mass index (BMI) which then categorized according to Asia Pacific classification to determine nutritional status.

Blood pressure measurement was performed by using a sphygmomanometer (A\&D Medical) and a stethoscope (Riester). Blood pressure data included systolic and diastolic blood pressure. Lipid profile laboratory examinations were performed after a period of minimal 10 hours fasting by using spectrophotometry method.

Carotid IMT examination was performed by using an ultrasound machine (Logiq E) with a high frequency linear transducers $(7-12 \mathrm{MHz})$. Subjects were asked to rest comfortably in the supine position, neck slightly extended with the head turned 45 degrees in the opposite direction from the part to be examined. The examiner was on the side of the subject or above the subject's head. The examination began by attaching the transducer from the supraclavicle directed towards the cranial to the mandibular angles. Examination was carried out twice on the right and left necks in each of the two places - the common carotid artery and internal carotid artery.

\section{Statistical Analysis}

Data analyzed by using Statistical Package for Social Sciences (SPSS) version 20.0. Univariate analysis with normality test Kolmogorov-Smirnov was performed in continuous data. Normally distributed data $(\mathrm{p} \geq 0.05)$ is presented with mean and standard deviation, when not normally distributed $(\mathrm{p}<0.05)$ data is presented as median and minimum-maximum range. Categorical data is presented in the form of frequency distribution $(\mathrm{n} \%)$. Bivariate analysis to assess correlation between fructose intake and carotid IMT is using Pearson or Spearman correlation test. Similar assessments were performed between age, lipid profile, blood pressure, BMI, waist circumference, physical activities, smoking and food intake (carbohydrate, protein, fat, fiber) and carotid IMT with levels of significance $p<0.05$.

\section{Results}

Table 1 shows median age of subjects in this study i.e. 41 years old, $72.3 \%$ of them have high education levels, and $91.5 \%$ of these individuals earn sufficient income.

Table 1. Baseline Characteristics Data of Subjects $(\mathrm{n}=47)$

\begin{tabular}{lc}
\hline Variables & Result \\
\hline Age (year-old) & $41(31-45)^{1}$ \\
Education, n(\%): & \\
Low & - \\
Middle & $13(27.7)$ \\
High & $34(72.3)$ \\
Income, $n$ (\%): & $4(8.5)$ \\
Low & $43(91.5)$ \\
Sufficient & \\
\hline
\end{tabular}

${ }^{1}:$ median (minimum-maximum)

Subjects underwent lipid profile laboratory examination comprising LDL, HDL and triglyceride whose results are presented in Table 2. Subjects' mean LDL level was $164.26 \pm 27.93$ $\mathrm{mg} / \mathrm{dl}$ with $57.4 \%$ classified as high and very high levels, mean HDL level was $45.51 \pm 9.82 \mathrm{mg} / \mathrm{dl}$ 
with a considerable proportion $29.8 \%$ within low category while median triglyceride level was 154 $(113-208) \mathrm{mg} / \mathrm{dl}$ with around $27.6 \%$ categorized as high and very high.

Most of subjects have normal blood pressure both systolic and diastolic. Systolic blood pressure median was $120(110-130) \mathrm{mmHg}$ with $6.4 \%$ categorized as high while diastolic blood pressure median was $80(70-80) \mathrm{mmHg}$ with $17.0 \%$ categorized as high.

According to nutritional status based on BMI $72.3 \%$ subjects were obesity. In addition, from waist circumference measurement around $66.0 \%$ subjects have central obesity with mean waist circumference of $94.41 \pm 9.23 \mathrm{~cm}$. Also it can be found that $48.9 \%$ subjects were in light physical activities category.

Table 2 also shows that most of subjects are categorized as light smokers i.e. in $93.6 \%$ and from carotid IMT ultrasound examination results a median of $1(0.8-1.4) \mathrm{mm}$ was observed with
$63.8 \%$ categorized as not normal/developing thickening.

In Table 3, it shows that median total energy intake of subjects was 1209 (1020-1645) $\mathrm{kcal} /$ day. Carbohydrate intake in most of subjects were considered sufficient i.e. in $59.6 \%$ subjects, similar observation with protein and fat intake that is $87.2 \%$ and $44.7 \%$ respectively, while fibers intake was considered insufficient in all subjects $(100 \%)$. It can also be found from the table that mean fructose intake of subjects was $31.97 \pm 15.48$ gram/day.

Results from this study shows that by using Spearman correlation test, no significant correlation was observed between fructose intake and carotid IMT $(r=0.148, p=0.320)$, that can be seen in Table 4. In this study correlation tests were also performed between age, lipid profile (LDL, HDL, triglyceride), blood pressure, BMI, waist circumference, physical activities, smoking, food intake (carbohydrate, protein, fat, fiber) and carotid IMT.

Table 2. Subject Characteristic Distribution Based on Lipid Profile, Blood Pressure, Nutritional Status, Waist Circumference, Physical Activities, Smoking, and Carotid Intima-Media Thickness $(n=47)$

\begin{tabular}{cc}
\hline Variables & Result \\
\hline Lipid Profile : & $164.26 \pm 27.93^{2}$ \\
LDL (mg/dl): & $1(2.1)$ \\
Optimal, n(\%) & $2(4.2)$ \\
Near optimal, n(\%) & $17(36.2)$ \\
Borderline high, n(\%) & $19(40.4)$ \\
High, n(\%) & $8(17.0)$ \\
Very High, n(\%) & $45.51 \pm 9.82^{2}$ \\
HDL (mg/dl): & $14(29.8)$ \\
Low, n(\%) & $31(66.0)$ \\
Normal, $(\%)$ & $2(4.3)$ \\
High, n(\%) & $154(113-208)^{1}$ \\
Triglyceride (mg/dl): & $21(44.7)$ \\
Normal, $(\%)$ & $13(27.7)$ \\
Borderline high, n(\%) & $12(25.5)$ \\
High, n(\%) & $1(2.1)$ \\
Very High, $\mathrm{n}(\%)$ & $120(110-130)^{1}$ \\
Systolic Blood Pressure (mmHg): & $44(93.6)$ \\
Normal, $\mathrm{n}(\%)$ & $3(6.4)$ \\
High, $\mathrm{n}(\%)$ & $80(70-80)^{1}$ \\
Diastolic Blood Pressure (mmHg): & $39(83.0)$ \\
Normal, n(\%) & $8(17.0)$ \\
High, n(\%) &
\end{tabular}


Table 2. (continued)

\begin{tabular}{lc}
\hline Variables & Result \\
\hline BMI $\left(\mathrm{kg} / \mathrm{m}^{2}\right)$ & $26.73 \pm 3.69^{2}$ \\
Nutritional Status according to BMI,n(\%): & - \\
Underweight & $7(14.9)$ \\
Normal & $6(12.8)$ \\
At risk & $27(57.4)$ \\
Obesity 1 & $7(14.9)$ \\
Obesity 2 & $94.41 \pm 9.23^{2}$ \\
Waist circumference (cm): & $16(34)$ \\
Normal, n(\%) & $31(66)$ \\
Central obesity, n(\%) & $1.7(1.63-1.77)^{1}$ \\
Physical Activities: & $23(48.9)$ \\
Light, $\mathrm{n}(\%)$ & $21(44.7)$ \\
Moderate, $\mathrm{n}(\%)$ & $3(6.4)$ \\
High, $\mathrm{n}(\%)$ & $44(93.6)$ \\
Smoking,n(\%): & $3(6.4)$ \\
Light & - \\
Moderate & $1(0.8-1.4)^{1}$ \\
Heavy & $17(36.2 \%)$ \\
Carotid intima-media thickness (mm): & $30(63.8 \%)$ \\
Normal, n(\%) &
\end{tabular}

HDL: high density lipoprotein, BMI: body mass index, LDL: low density

lipoprotein

1 : median (minimum-maximum)

$2:$ mean \pm standard deviation

Table 3. Subject Characteristics Distribution Based on Total Energy, Carbohydrate, Protein, Fat, Fibers and Fructose Intake $(\mathrm{n}=47)$

\begin{tabular}{cc}
\hline Variables & Result \\
\hline Total energy intake (kcal/day) & $1209(1020-1645)^{1}$ \\
Carbohydrate intake (gram/day): & $183 \pm 55.53^{*}$ \\
Insufficient, $\mathrm{n}(\%)$ & $6(12.8)$ \\
Sufficient, $\mathrm{n}(\%)$ & $28(59.6)$ \\
Over sufficient, n(\%) & $13(27.7)$ \\
Protein intake (gram/day): & $44.1(32.4-55.1)^{1}$ \\
Insufficient, n(\%) & $6(12.8)$ \\
Sufficient, $\mathrm{n}(\%)$ & $41(87.2)$ \\
Over sufficient, $\mathrm{n}(\%)$ & - \\
Fat intake (gram/day): & $41.43 \pm 22.76^{2}$ \\
Insufficient, $\mathrm{n}(\%)$ & $13(27.7)$ \\
Sufficient, $\mathrm{n}(\%)$ & $21(44.7)$ \\
Over sufficient, $\mathrm{n}(\%)$ & $13(27.7)$ \\
Fibers intake (gram/day): & $6.3(4.6-9.6)^{1}$ \\
Insufficient, $\mathrm{n}(\%)$ & $47(100)$ \\
Sufficient, $\mathrm{n}(\%)$ & - \\
Fructose intake (gram/day) & $31.97 \pm 15.48^{2}$ \\
\hline
\end{tabular}


result that no significant correlation between age, lipid profile, blood pressure, BMI, physical activities, smoking, carbohydrate, protein, and fiber intake and carotid IMT. However, significant positive correlation was found between waist circumference $(\mathrm{r}=0.330, \mathrm{p}=0.023)$ and fat intake $(\mathrm{r}=0.330, \mathrm{p}=0.024)$ and carotid IMT.

As observed in Table 4, dominant factors $(\mathrm{p}<0.25)$ related to carotid IMT are LDL, HDL, systolic blood pressure, BMI, waist circumference and fat intake. Further analysis with multiple linear regression test was performed as presented in Table 5. Analysis result found that only fat intake has a statistically significant correlation to carotid IMT with $\mathrm{p}=0.015$.

Table 4. Correlation between Fructose Intake, Age, Lipid Profile, Blood Pressure, Body Mass Index, Waist Circumference, Physical Activity, Smoking, Food Intake and

Carotid Intima-Media Thickness $(\mathrm{n}=47)$

\begin{tabular}{lcc}
\hline Variables & \multicolumn{2}{c}{ Carotid Intima-Media Thickness (mm) } \\
\cline { 2 - 3 } & $\mathbf{r}$ & $\boldsymbol{P}$ \\
\hline Age (years-old) & 0.163 & $0.274^{\mathrm{S}}$ \\
Lipid Profile: & & \\
$\quad$ LDL (mg/dl) & 0.207 & $0.163^{\mathrm{S}}$ \\
HDL (mg/dl) & -0.188 & $0.206^{\mathrm{S}}$ \\
Triglyceride (mg/dl) & -0.007 & $0.962^{\mathrm{S}}$ \\
Systolic Blood Pressure (mmHg) & 0.242 & $0.102^{\mathrm{S}}$ \\
Diastolic Blood Pressure (mmHg) & 0.087 & $0.561^{\mathrm{S}}$ \\
BMI (kg/m ${ }^{2}$ ) & 0.234 & $0.114^{\mathrm{S}}$ \\
Waist circumference (cm) & 0.330 & $\mathbf{0 . 0 2 3}^{\text {领 }}$ \\
Physical activities & -0.159 & $0.285^{\mathrm{S}}$ \\
Smoking & 0.045 & $0.762^{\mathrm{S}}$ \\
Food intake : & & \\
$\quad$ Carbohydrate (gram/day) & -0.019 & $0.900^{\mathrm{S}}$ \\
$\quad$ Protein (gram/day) & 0.118 & $0.429^{\mathrm{S}}$ \\
$\quad$ Fat (gram/day) & 0.330 & $\mathbf{0 . 0 2 4}$ \\
$\quad$ Fiber (gram/day) & -0.003 & $0.983^{\mathrm{S}}$ \\
Fructose (gram/day) & 0.148 & $0.320^{\mathrm{S}}$ \\
\hline
\end{tabular}

$p$ : levels of significance $<0.05$, r: correlation,

HDL: high density lipoprotein, BMI: body mass index, LDL: low density lipoprotein, ${ }^{\mathrm{s}}$ : Spearman test,

\#: statistically significant

\section{Discussion}

Correlation between Fructose Intake and Carotid Intima-Media Thickness

This study is aimed to seek correlation between fructose intake and carotid IMT. Study result demonstrated that no significant correlation was found between fructose intake and carotid IMT ( $\mathrm{r}$ $=0.148, p=0.320$ ). Study on fructose intake and its relation with carotid IMT assessed by IMT ultrasound examination is still limited. Soo et.al. ${ }^{14}$ conducted a study regarding high fructose intake and its correlation with cardiovascular disease in rats that in growing period, one of the parameter assessed is the abdominal aorta wall thickness as a marker of the presence of atherosclerosis. Result suggested that in rats fed with high fructose diet (regular diet with 30\% fructose) have thicker abdominal aorta wall compared to those fed on regular diet, mean thickness of $23.6 \pm 0.9 \mu \mathrm{m}$ on high fructose diet compared to mean thickness of $18.5 \pm 0.5 \mu \mathrm{m}$ on regular diet. In this study result, no correlation was found between fructose intake 
during interview using semi-quantitative food frequency questionnaire, that is due to lack of subjects' recall on food intake, inaccuracy in food estimation, portion/serving and intake frequency. Lack information on fructose content in industrial food/beverages may also cause lack of data on fructose intake in this study subjects. Carotid intima-media thickness can be used as an initial marker or early diagnosis of atherosclerosis. According to several studies, high fructose intake may become on of the risk factors for atherosclerosis. This is because high fructose intake significantly correlated with DNL activity increase that resulted in increased blood cholesterol levels.. ${ }^{7,13}$

In this study subjects, most of them have already developed carotid wall thickness hence advised to control/limit fructose intake particularly derived from food and beverage containing artificial sweetener substances to prevent increasing risk of atherosclerosis.

Correlation between Age, Lipid Profile, Blood Pressure, Body Mass Index, Waist Circumference, Physical Activity, Smoking, Food Intake and Carotid Intima-Media Thickness

This study also performed tests to correlate age, lipid profile, blood pressure, BMI, waist circumference, physical activity, smoking, and food intakes with carotid IMT. Results showed no significant correlation between age, lipid profile, blood pressure, BMI, physical activity, smoking, food intake (carbohydrate, protein and fibers) and carotid IMT. However, positive significant correlation was found between waist circumference $(\mathrm{r}=0.330, \mathrm{p}=0.023)$ and fat intake $(\mathrm{r}=0.330, \mathrm{p}$ $=0.024)$ to carotid IMT. Meanwhile in multivariate analysis of dominant factors $((\mathrm{p}<0.25)$ resulted in statistical correlation only between fat intake and carotid IMT ( $p=0.015)$.

Similar result was reported in a study by Mulyanto ${ }^{16}$ on 62 subjects aged 36-77 years old in Semarang that fat intake $(\mathrm{p}=0.011)$ and age $(\mathrm{p}$ $=0.005)$ have significant correlation with carotid IMT. Fat intake particularly saturated fatty acids usually from animal when consumed excessively will significantly increase LDL cholesterol levels. A number of studies performed analysis that suggested that every $1 \%$ increase in calories from saturated fats will resulted in $2 \%$ increase in LDL levels. High levels of LDL especially those of oxidized one may cause damage and thickening of the blood vessel walls. ${ }^{4}$ Different from study by Azarpazhooh et.al. ${ }^{17}$ on 431 subjects aged 35-64 years old in Iran that found significant correlation between age $(\mathrm{r}=0.56, \mathrm{p}<0.001)$, BMI $(\mathrm{r}=0.12$, $\mathrm{p}$ $<0.05)$, systolic blood pressure $(r=0.22, p<0.01)$, diastolic blood pressure $(r=0.19, p<0.01)$ and carotid IMT and from multivariate analysis it was demonstrated that age $(p<0.01)$ and male gender $(p$ $<0.05)$ were significant predictor of IMT. Meanwhile in study by Jarauta et.al. ${ }^{18}$ on 138 subjects aged 20-79 years old di Spain found that significant factors to IMT were age $(p<0.001)$, male gender $(\mathrm{p}=0.027)$, systolic blood pressure $(\mathrm{p}$ $=0.029)$ and LDL $(p=0.029)$. A longitudinal study in 13 years conducted by Herder et.al ${ }^{19}$ di Norway on 2,743 subjects aged 55-74 years old aiming to study long term risk factors and factors affecting IMT progressivity suggested that age and gender were strong predictors for IMT and total cholesterol was a predictor for IMT progressivity.

As recognized from several studies above that male gender is an influencing factor for carotid IMT. In this study, male gender is a controlled variable. Adult male individual has an increased risk of cardiovascular disease compared to female. Pre-menopausal women are relatively more protected against atherosclerosis compared to men of the same ages, without any other risk factors such as obesity, diabetes mellitus, dyslipidemia, or hypertension. Behavior and lifestyle may also affect increased risks in men such as smoking habits, alcohol drinking and poor eating pattern. ${ }^{20,21}$ In this study age did not have significant correlation with carotid IMT. This when compared to other previous studies may be due to difference in age criteria in study subjects that is difference in age range. In older ages the possibility of carotid wall thickening development is greater. Age is a non modifiable risk factor for cardiovascular disease, risk increases as age progresses. To anticipate it modification of other risk factors is needed. In atherosclerosis, plaque accumulation develops over the course of years, progressive in nature and usually do not manifest clinically until 
reaching critical threshold in the middle or older ages. $^{20,22}$

\section{Conclusion}

In this study there was no correlation between fructose intake and carotid IMT. Waist circumference and fat intake have positive significant correlations with carotid IMT. Further multivariate analysis showed that fat intake has a significant positive correlation with carotid IMT.

\section{Conflict of Interest}

Authors declare there was no conflict of interest regarding this study.

\section{Open Access}

This article is distributed under the terms of the Creative Commons Attribution 4.0 International Licence (http://creativecommons.org/licenses/by/4.0/), which permits unrestricted use, distribution, and reproduction in any medium, provided you give appropriate credit to the original author(s) and the source, provide a link to the Creative Commons license, and indicate if changes were made.

\section{Reference}

1. World Health Organization. Cardiovascular diseases (CVDs). 2016.[cited 2017 Jan] http://www.who.int/mediacentre/factsheets/fs 317/en/

2. Barquera S, Pedroza-Tobias A, Medina A, Hernandez-Barrera L, Bibbins-Domingo K, Lozano R. Global Overview of the Epidemiology of Atherosclerotic Cardiovascular Disease. Archieves of Medical Research 2015;46(5):328. [Google Scholar]

3. Singh RB, Mengi SA, Yan-Jun X, Ameja AS, Dhalla NS. Pathogenesis of atherosclerosis: A multifactorial process. Experimental and Clinical Cardiology 2002;7(1):40. [Google Scholar]
4. Perhimpunan Dokter Spesialis Kardiovaskular Indonesia. Pedoman Tatalaksana Dislipidemia. 2013.

5. Ferrieres J. Lipoprotein Effects on Coronary Atherosclerosis by Targeting Low-Density Cholesterol with Statins. American Journal for Cardiovascular Drugs 2009;9(2):109. [Google Scholar]

6. Gullace G, Khalaf H. Preclinical Diagnosis and Risk Assessment of Atherosclerosis-At Birth? At Event? When is Best. European Cardiology 2011;7(3):164-6. [Google Scholar]

7. Muis M, Murtala B. Peranan Ultrasonografi dalam Menilai Kompleks Intima-media Arteri Karotis untuk Diagnosis Dini Aterosklerosis. CDK 2011;38(3):231. [Google Scholar]

8. Amuamuta A. A Review on Risk Factors/Indicators and Effects of Hyperlipidemia. Middle-East Journal of Scientific Research 2014;22(6):886. [Google Scholar]

9. Merchant AT, Anand SS, Kelemen LE, Vuksan V, Jacobs R, Davis B. 2007). Carbohydrate intake and HDL in a multiethnic population. The American Journal of Clinical Nutritio 2007;85(1):225. [Google Scholar]

10. Studi Diet Total : Survei Makanan. Badan Penelitian dan Pengembangan Kesehatan. 2014

11. Almatsier, Sunita. Prinsip Dasar Ilmu Gizi. Jakarta: Gramedia Pustaka Utama.2005:31

12. Rizkalla SW. Health Implications of Fructose Consumption: A Review of Recent Data. Nutrition \& Metabolism 2010;7:82. [Google Scholar]

13. Kolderup A, Svihus B. Fructose Metabolism and Relation to Atherosclerosis, Type 2 Diabetes, and Obesity. Journal of Nutrition and Metabolism. 2015:823081.

14. Soo YY, Hyejin A, Yoo KP. High Dietary Fructose Intake on Cardiovascular Disease Related Parameters in Growing Rats. Nutrients 2017;9(1):11. [Google Scholar]

15. Bo N, Xiaoyan W, Ying Y, Waqar AB, Qi Y, Tomonari K. High-fructose and high-fat dietinduced insulin resistance enhances 
atherosclerosis in Watanabe heritable hyperlipidemic rabbits. Nutrition \& Metabolism 2015;12:30. [Google Scholar]

16. Mulyanto E. Hubungan Asupan Lemak dengan Ketebalan Tunika Intima-Media Arteri Karotis Interna pada Pasien Pasca Stroke Iskemik [tesis]. Ilmu Penyakit Saraf. Universitas Diponegoro Semarang. 2012

17. Azarpazhooh MR, Kazemi-Bajestani SMR, Esmaeili H, Vedadian P, Ebrahimi M, Parizadeh SMR. Cardiovascular Risk Factors and Nutritional Intake are not Associated with Ultrasound-defined increased Carotid Intima Media Thickness in Individuals without a History of Cardiovascular Events. International Journal of Preventive Medicine 2014;5(11):1412. [Google Scholar]

18. Jarauta E, Mateo-Gallego R, Bea A, Burillo E, Calmarza P, Civeira F. Carotid IntimaMedia Thickness in Subjects with No Cardiovascular Risk Factors. Revista Espanola de Cardiologia 2010;63(1):97. [Google Scholar]

19. Herder M, Johnsen SH, Arntzen KA, Mathiesen EB. Risk Factors for Progression of Carotid Intima-Media Thickness and Total Plaque Area. A 13-Year Follow-Up Study: The Thromso Study. Stroke AHA Journals 2012;43(7):1818. [Google Scholar]

20. Kumar V, Abbas AK, Aster JC. The Blood Vessel. In: Robbins Basic Pathology. Edisi ke-8. Philadelph: Elsevier. 2007:335-7.

21. Colafella KMM, Denton KM. Sex-Spesific Differences in Hypertension and Associated Cardiovascular Disease. Nature Reviews Nephrology 2018;14(3):185. [Google Scholar]

22. Dhingra R, Vasan RS. Age as a Cardiovascular Risk Factor. Med Clin North Am 2012;96(1):87. [Google Scholar] 